\title{
Influência do ligante na retração por secagem em fibrocimento
}

\author{
Influence of binder in the drying shrinkage of fiber \\ cement
}

\author{
Brunoro Leite Giordano \\ Rui Barbosa de Souza \\ Vanderley Moacyr John
}

\section{Resumo \\ $\mathbf{E}$} xiste um grande interesse das indústrias de fibrocimento em buscar ligantes de composição ótima do ponto de vista econômico, técnico e ambiental. Nesse sentido, cimentos em que parte do clínquer é substituída existe um grande interesse das indústrias de fibrocimento em buscar ligantes de composição ótima do ponto de vista econômico, técnico e ambiental. Neste sentido, cimentos onde parte do clínquer é substituída por adições ativas são bastante atrativos e cimentos com baixos teores de adição já são utilizados pelo setor. Entretanto, chapas de fibrocimento reforçadas com fibras orgânicas têm apresentado frequentemente fissuras nas bordas de telhas e painéis, que provém da secagem dos componentes nas pilhas de estocagem. Neste trabalho foi avaliado o impacto da introdução de escória e silicato de sódio na composição do ligante nas propriedades mecânicas, porosidade, compostos hidratados formados e principalmente na retração por secagem de fibrocimentos reforçados com fibras orgânicas. Foram produzidas placas de fibrocimento com cimento CPII F-32 e com uma mistura do CPII F-32 e escória granulada de alto forno ativada por silicato de sódio alcalino. Os resultados mostraram que há maior quantidade de poros menores que $0,003 \mu \mathrm{m}$ na amostra com escória e silicato de sódio, devido à maior quantidade de C-S-H formado na hidratação. Consequentemente, a

Brunoro Leite Giordano Programa de Pós-Graduação em

Engenharia Civil, Escola Politécnica

Universidade de São Paulo Avenida Prof. Luciano

Gualberto, Trav. 3, n. 380 São Paulo - SP - Brasil CEP 05088-900

Tel.: (11) 3091-5382 E-mail:

brunoro.giordano@poli.usp.br

Rui Barbosa de Souza Programa de Pós-Graduação em Engenharia Civil, Escola Politécnica

Universidade de São Paulo E-mail: rui.souza@poli.usp.br

Vanderley Moacyr John Programa de Pós-Graduação em Engenharia Civil, Escola Politécnica

Universidade de São Paulo Tel.: (11) 3091-5794
E-mail:

vanderley.john@poli.usp.br

Recebido em 21/07/09

Aceito em 16/11/09 incorporação de escória ativada com silicato de sódio como ligante do fibrocimento aumenta a retração por secagem deste compósito, aumentando consequentemente, a tendência da fissuração dos artefatos.

Palavras-chave: Filler calcário. Escória de alto-forno. Retração por secagem. Composição química.

\section{Abstract}

There has much interest in the fiber cement industry in improving binder composition in order to achieve better economic, technical and environmental results. In this context, cements with lower clinker content are an attractive alternative and have already been used by the industry. However, fibercement sheets reinforced with organic fibers frequently present edge cracks resulting from drying the components in stockpiles. This study evaluates the impact of partially replacing clinker by blast furnace slag activated with sodium silicate on the mechanical properties, porosity, hydrated phases, and drying shrinkage of fiber cement reinforced with organic fibers. Samples were produced with commercial Brazilian CPII F-32 cement and also with a mixture of CPII F-32 with granulated blast furnace slag activated by sodium silicate. The results show that replacing clinker by slag activated by sodium silicates increases the amount of pores smaller than $0.003 \mu \mathrm{m}$, due to an increase in the amount of CSH formed in hydration. Consequently, samples produced with CPII F-32 mixed with slag and sodium silicate present much higher drying shrinkage.

Keywords: Limestone filler. Blast furnace slag. Drying shrinkage. Chemical composition. 


\section{Introdução}

Componentes de fibrocimento produzidos pelo processo Hatschek, que são uma parte expressiva dos telhados brasileiros, possuem teor de cimento (ligante) muito acima do empregado em concretos e argamassas. A quantidade de ligante nas formulações de fibrocimento pode chegar a valores superiores a $80 \%$ da massa de materiais secos (DIAS et al., 2009), enquanto as formulações de concreto de alta resistência podem utilizar $25 \%$ desse valor (HOPPE FILHO, 2008).

Nesse cenário, existe um grande interesse das indústrias de fibrocimento em buscar ligantes de composição ótima do ponto de vista econômico, técnico e ambiental. Cimentos Portland como CPII E, CPII F e CPII Z, cuja parte do clínquer é substituída por adições ativas são bastante atrativos e já têm sido utilizados pelo setor. Existe também a possibilidade de utilização de ligantes com maior teor de adição, como CPIII e CPIV, que trazem enorme potencial para diminuir as emissões de $\mathrm{CO}_{2}$ na produção do cimento (CARVALHO, 2002), contribuindo para a mitigação do efeito estufa. Ocorre que cimentos com altos teores de adição possuem lenta evolução da resistência, o que dificulta a produção industrial. No entanto, a ativação de escórias e pozolanas por silicatos de sódio alcalino geram ligantes com rápido ganho de desempenho mecânico (JOHN, 1995; JIMENEZ et al., 2005; SHI; KRIVENKI; ROY, 2006).

Variações na composição do cimento, mesmo as já comuns substituições do clínquer por adições ativas, provocam não apenas alterações na velocidade de ganho de resistência, mas também a cinética de hidratação do cimento afetando o calor de hidratação e modificam as fases mineralógicas e a microestrutura do compósito endurecido (SCRIVENER; WIEKER, 1992, JOHN, 1995). Os efeitos práticos dessas alterações muitas vezes não são perceptíveis no dia-a-dia da aplicação dos diferentes tipos cimentos Portland em concretos, mas os fibrocimentos são potencialmente mais sensíveis a estas alterações, devido ao seu alto teor de ligante.

Os produtos hidratados dos ligantes com adições de escória e pozolanas ou de cimento de escória ativada com silicato de sódio contêm uma quantidade de silicato de cálcio hidratado (C-S-H) mais elevada do que o cimento Portland comum. A maior quantidade de C-S-H está associada na literatura, entre outras coisas, a um aumento da retração por secagem. Melo Neto (2002) mostrou que a retração por secagem de cimentos de escória ativada com silicato de sódio gera retração entre 2 e 8 vezes maior que o cimento Portland comum. Entretanto, existem poucos estudos da retração desses ligantes em formulações de compósitos típicas dos fibrocimentos.

Compósitos de fibrocimento com fibras orgânicas vêm sendo fabricados de forma crescente no Brasil. Esses compósitos têm apresentado frequentemente fissuras nas bordas de telhas e painéis, que ocorre durante a secagem dos componentes nas pilhas de estocagem. Por esse motivo a avaliação da retração por secagem nesses compósitos cimentícios é essencial. Estudos realizados por Akers e Garrett (1983) e Akers e Partl (1990) mostraram que as tensões desenvolvidas por gradientes de umidade dentro de componentes de fibrocimento são a maior causa da fissuração.

Este trabalho tem como objetivo avaliar o impacto na mudança da composição de ligantes pela introdução de escória granulada e silicato de sódio, nas propriedades mecânicas e retração por secagem de compósitos cimentícios reforçados com fibras orgânicas.

\section{Materiais e métodos}

Para uma avaliação mais criteriosa da mudança da composição dos ligantes foram adotadas as metodologias descritas a seguir com a técnica de retração por secagem, grau de hidratação, desempenho mecânico e porosidade. Os corpos de prova de fibrocimento foram produzidos com cimento CPII F-32 e comparados com os confeccionados com uma mistura do CPII $\mathrm{F}$ e escória granulada de alto-forno (composição que se enquadra como um cimento do tipo CPIII segundo a NBR 5735 (ABNT, 1991)) ativada por silicato de sódio alcalino, identificado pela sigla CPII F+E

Para a produção dos corpos-de-prova foi utilizado um cimento Portland CPII F-32 produzido comercialmente no mercado nacional. Para a produção do cimento CPII F+E, utilizou-se escória granulada de alto-forno básica, com relação $\mathrm{CaO} / \mathrm{SiO}_{2}$ igual a 1,31. O silicato de sódio alcalino utilizado possui módulo de sílica $\left(\mathrm{SiO}_{2} / \mathrm{Na}_{2} \mathrm{O}\right)$ igual a 1,7 , com $16,7 \%$ de $\mathrm{Na}_{2} \mathrm{O}$ e $54,9 \%$ de água em massa. A caracterização detalhada da escória e do silicato de sódio está apresentada em Melo Neto (2007). O filler empregado é um calcário magnesiano proveniente da região Sul do Brasil. Foi usada sílica ativa não densificada. As fibras orgânicas empregadas foram celulose de eucalipto branqueada originária do mercado nacional e fibra de PVA com $6 \mathrm{~mm}$ de comprimento e diâmetro aproximado de $13 \mu \mathrm{m}$, oriunda da China. 
A Figura 1 apresenta a distribuição granulométrica, discreta e acumulada, obtida por difração a laser (equipamento MASTERSIZER S) dos materiais particulados. Observa-se que conforme a literatura o diâmetro das partículas de sílica ativa é da ordem de $0,1 \mu \mathrm{m}$. No entanto, a distribuição granulométrica da Figura 1 mostra que as partículas de sílica apresentam diâmetros entre $0,1 \mu \mathrm{m}$ e $300 \mu \mathrm{m}$, com média igual a $11,86 \mu \mathrm{m}$, demonstrando que o material encontra-se aglomerado, ocorrência discutida na literatura (ROMANO et al, 2008)

\section{Produção dos corpos de prova de fibrocimento}

As mantas de fibrocimento, $200 \mathrm{~mm} \times 200 \mathrm{~mm}$, foram fabricadas seguindo as formulações (Tabela 1) tipicamente utilizadas pelas indústrias nacionais, através do método de drenagem a vácuo utilizado por Savastano Júnior. (2001-2004). Os materiais foram misturados em agitador mecânico IKA

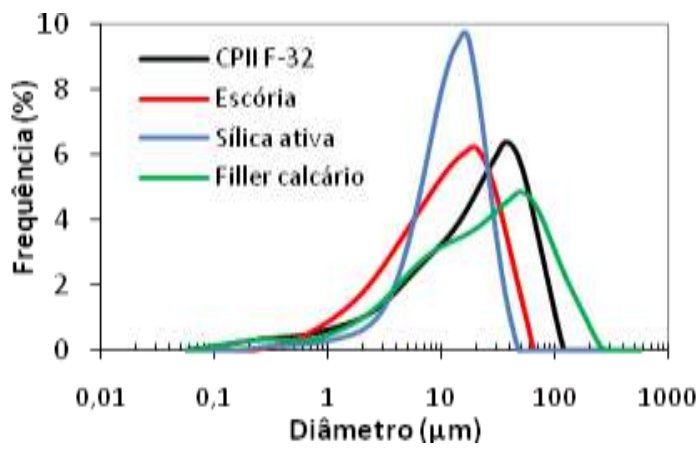

(a) Curva discreta
(Labortechnik RW20) a $2000 \mathrm{rpm}$ e adicionados na sequência: água $\rightarrow$ polpa de celulose $(2,5 \mathrm{~min})$ $\rightarrow$ fibra sintética (2,5 min) $\rightarrow$ minerais - cimento, escória, filler calcário e sílica ativa (3 min), formando uma suspensão aquosa com $20 \%$ de sólidos. Após a mistura, a suspensão foi despejada num recipiente especial onde recebeu uma pressão de vácuo $(200 \mathrm{mmHg})$ para a retirada da água em excesso, conformando uma manta de espessura de $2,5 \mathrm{~mm}$.

As placas de fibrocimento foram produzidas mediante a superposição de três mantas, em processo similar ao que acontece em máquinas Hatschek. Entre duas mantas de CPII F+E foi aplicada com um pincel a solução de silicato de sódio, com consumo aproximado de $0,25 \mathrm{~g} / \mathrm{cm}^{2}$. O silicato tem por objetivo ativar a escória de altoforno presente na formulação. Por fim, as placas constituídas de três camadas foram prensadas a uma tensão máxima de $3,2 \mathrm{MPa}$ pelo período de 5 min. A espessura final dos corpos de prova é de 7,0 $\mathrm{mm}$.

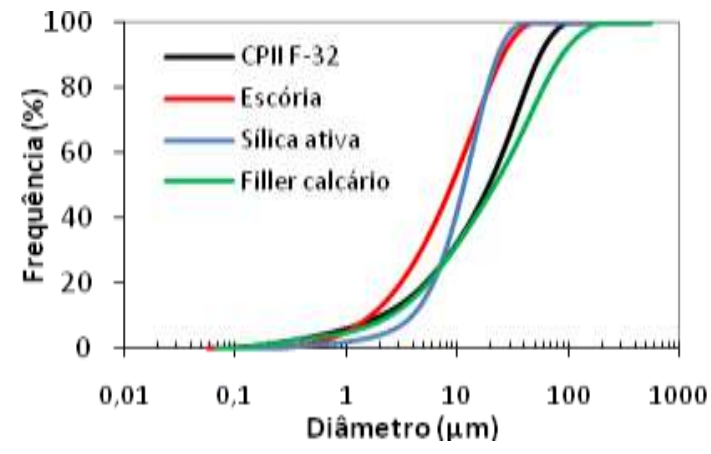

(b) Curva acumulada

Figura 1 - Distribuição granulométrica das matérias-primas

\begin{tabular}{l|r|r}
\hline & CPII-F & CPII-F+E \\
\hline Água & 76,2 & 75,8 \\
\hline Cimento CPII F-32 & 13,2 & 5,2 \\
\hline Escória de alto-forno & - & 8,3 \\
\hline Filler calcário & 7,2 & 7,2 \\
\hline Sílica ativa & 1,6 & 1,6 \\
\hline Fibras orgânicas total & 1,9 & 1,9 \\
\hline Soma & $\mathbf{1 0 0 , 0}$ & $\mathbf{1 0 0 , 0}$ \\
\hline
\end{tabular}

Tabela 1 - Fração em volume (\%) para os fibrocimentos 


\section{Cura e retração por secagem}

A cura térmica dos fibrocimentos foi realizada em câmara climática à temperatura de $60 \pm 5{ }^{\circ} \mathrm{C}$ e umidade relativa de $90 \%$ por $72 \mathrm{~h}$. Após a cura inicial as placas foram cortadas com disco diamantado, na geometria de $160 \mathrm{~mm} \mathrm{x} 40 \mathrm{~mm}$, sendo produzidos 6 corpos de prova por série. As bordas dos corpos de prova foram impermeabilizadas com verniz poliuretano para garantir a perda de água somente pela superfície. Nas extremidades foram coladas com massa plástica as bases metálicas para leitura do comprimento. Em seguida, realizou-se a primeira leitura de comprimento (Figura 2) e obteve-se a massa (precisão de $0,01 \mathrm{~g}$ ).

A seguir os corpos de prova foram mantidos em câmara climática à temperatura de $23 \pm 5{ }^{\circ} \mathrm{C}$ e umidade relativa de $50 \%$ até 28 dias para avaliação da retração por secagem. Ao final do ensaio foi determinada, através da metodologia utilizada para concretos e argamassas (ABNT, 2005), a massa seca, saturada e imersa para a obtenção de umidade residual, absorção de água e porosidade total.

\section{Propriedades mecânicas}

As propriedades mecânicas foram determinadas por meio dos corpos de prova utilizados no ensaio de retração por secagem até os 28 dias. Antes do ensaio, os corpos de prova foram imersos por $24 \mathrm{~h}$ em água saturada com hidróxido de cálcio para garantir homogeneidade de umidade através da saturação completa dos poros, sem lixiviação do hidróxido de cálcio da pasta de cimento. A resistência mecânica dos fibrocimentos foi determinada através do ensaio à flexão com 4 pontos, utilizando uma prensa universal INSTRON (modelo 5569) com célula de carga de $1 \mathrm{kN}$ e sensor de deslocamento Solartron com curso de 5,0 mm, posicionado na região central do vão, para medir a deformação. A velocidade de deslocamento foi controlada $(5,0 \mathrm{~mm} / \mathrm{min})$. A partir desse ensaio, foram determinados o módulo de ruptura (MOR), o módulo de elasticidade (MOE), o limite de proporcionalidade (LOP) e a tenacidade dos compósitos. Utilizaram-se 6 corpos de prova por série.

\section{Distribuição dos poros}

Através de um porosímetro de intrusão de mercúrio, MICROMERITICS (modelo Auto Pore III), foi caracterizada a distribuição de poros. Os ensaios foram realizados em amostras de aproximadamente $1,0 \pm 0,2 \mathrm{~g}$, retiradas dos corpos de prova após o ensaio de flexão com disco diamantado de precisão. As amostras foram extraídas de uma região próxima aos apoios e central dos corpos de prova para evitar trechos fissurados. Antes do ensaio, as amostras foram secas em estufa por $48 \mathrm{~h}$ à temperatura de $60 \pm 5$ ${ }^{\circ} \mathrm{C}$. Foram ensaiadas duas amostras por série.

Utilizou-se a Equação de Washburn para a determinação da distribuição dos tamanhos dos poros. Foram utilizados para os cálculos ângulo de contato igual a $130^{\circ}$ e tensão superficial do mercúrio igual a $485 \times 10^{-3} \mathrm{~N} / \mathrm{m}$ (SATO, 1998). Embora alguns autores como Diamond (2000) considerem a porosimetria de mercúrio inapropriada para medir a distribuição dos tamanhos dos poros de materiais cimentícios, outros autores empregaram essa técnica de forma eficiente na comparação da estrutura de poros (JOHN, 1995; DIAS, 2005; MELO NETO; CINCOTTO, 2008; HOPPE FILHO, 2008).

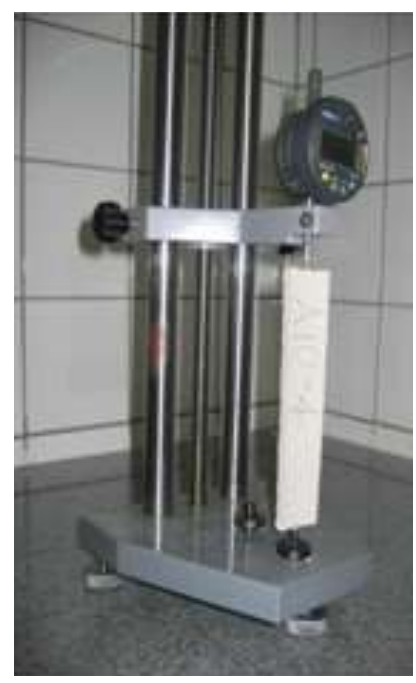




\section{Análise termogravimétrica}

A termogravimetria foi realizada em uma termobalança NETZSCH modelo STA 409 PG. As amostras, de aproximadamente $1,0 \mathrm{~g}$, foram congeladas em freezer a $-20^{\circ} \mathrm{C}$ a seguir liofilizadas e posteriormente moídas em almofariz. Padronizou o ensaio, mantendo a massa das amostras em $1,0 \pm 0,001 \mathrm{~g}$, com o intuito de minimizar distorções dos resultados provenientes da quantidade de massa heterogênea (TAYLOR, 1997; HOPPE FILHO, 2008). O ensaio foi realizado em atmosfera de gás nitrogênio, com taxa de 60 $\mathrm{ml} /$ minuto, para melhor quantificação dos compostos inerentes ao fibrocimento. Foi adotada uma taxa de aquecimento de $10{ }^{\circ} \mathrm{C} / \mathrm{min}$ varrendo de $30{ }^{\circ} \mathrm{C}$ a $1.000{ }^{\circ} \mathrm{C}$, em cadinho de alumina com volume de $3,4 \mathrm{ml}$.

A partir dos resultados da análise termogravimétrica, é possível quantificar a decomposição dos voláteis, entre outros, a quantidade de água combinada em diferentes fases do cimento hidratado.

\section{Resultados e discussões}

\section{Porosidade}

A Tabela 2 resume os principais resultados de porosidade dos compósitos. Os valores médios de absorção em água e porosidade total medida em água se mostraram equivalentes para compósitos produzidos com os dois cimentos. No entanto, os dados de porosimetria de mercúrio revelam que a distribuição de poros é muito diferente (Figura 3). $\mathrm{O}$ volume total de mesoporos $(0,003 \mu \mathrm{m}<\mathrm{d}<$ $50 \mathrm{~nm})$ foi levemente superior para o compósito CPII F+E, mas esse compósito apresentou volume de poros abaixo de $30 \mathrm{~nm}$, típico do espaço interlamelar do C-S-H (MEHTA; MONTEIRO, 2008), muito superior ao CPII F. Isso se deve, predominantemente, à hidratação do sistema escória de alto-forno e silicato de sódio (MELO NETO, 2008).

Os poros do intervalo II (entre $0,2 \mu \mathrm{m}$ e $10 \mu \mathrm{m}$ ) são associados por Dias (2005) ao lúmen da celulose, que provavelmente foi degradada pela ação alcalina do silicato de sódio da formulação CPII F+E. No entanto, essa conclusão precisa ser confirmada por estudos complementares. Os poros acima de $10 \mu \mathrm{m}$ (Faixa III) revelam nesse tipo de produto a ocorrência de defeitos de moldagem, como a aglomeração de fibras.

\section{Propriedades mecânicas}

O limite de proporcionalidade (LOP) da matriz e o módulo de ruptura (MOR) não sofreram alteração para ambos os ligantes (Tabela 3). O módulo de elasticidade (Tabela 3) na flexão foi maior nas amostras com cimento CPII F. Esse baixo módulo de elasticidade pode ser ao menos parcialmente atribuído a defeitos de aderência entre camadas gerados pela retração diferencial dos ligantes, introduzida pela presença de silicato de sódio e escória, sistema que tem retração muito mais elevada que o do cimento original. Melo Neto (2002) mostra que argamassas de cimento de escória ativada com silicato de sódio curadas a seco apresentam aos 28 dias $54 \%$ das confeccionadas com cimento Portland (CPV-ARI). A tenacidade pode ser considerada igual para os dois compósitos (Figura 4), apesar da provável destruição das fibras de celulose na formulação $\mathrm{CPII} F+\mathrm{E}$.

\begin{tabular}{c|c|c}
\hline & CPII F & CPII F+E \\
\hline Porosidade total em água $(\mathbf{m l} / \mathbf{g})$ & 0,359 & 0,378 \\
\hline Absorção de água $(\mathbf{g} / \mathbf{g})$ & 0,226 & 0,233 \\
\hline Intrusão de mercúrio $(\mathbf{m l} / \mathbf{g})$ & 0,182 & 0,140 \\
\hline Poros $0,003<\mathbf{0 , 0 5 0} \boldsymbol{\mu m}(\mathbf{m l} / \mathbf{g})$ & 0,071 & 0,076 \\
\hline Poros $<\mathbf{0 , 0 0 3} \boldsymbol{\mu m}(\mathbf{m l} / \mathbf{g})$ & 0,044 & 0,093 \\
\hline
\end{tabular}

Nota: os valores de poros $<0,003 \mu \mathrm{m}$ foram produzidos pela combinação de absorção de água e intrusão total de mercúrio

Tabela 2 - Valores de absorção e porosidade em água bem como resultados de porosimetria por intrusão de mercúrio 


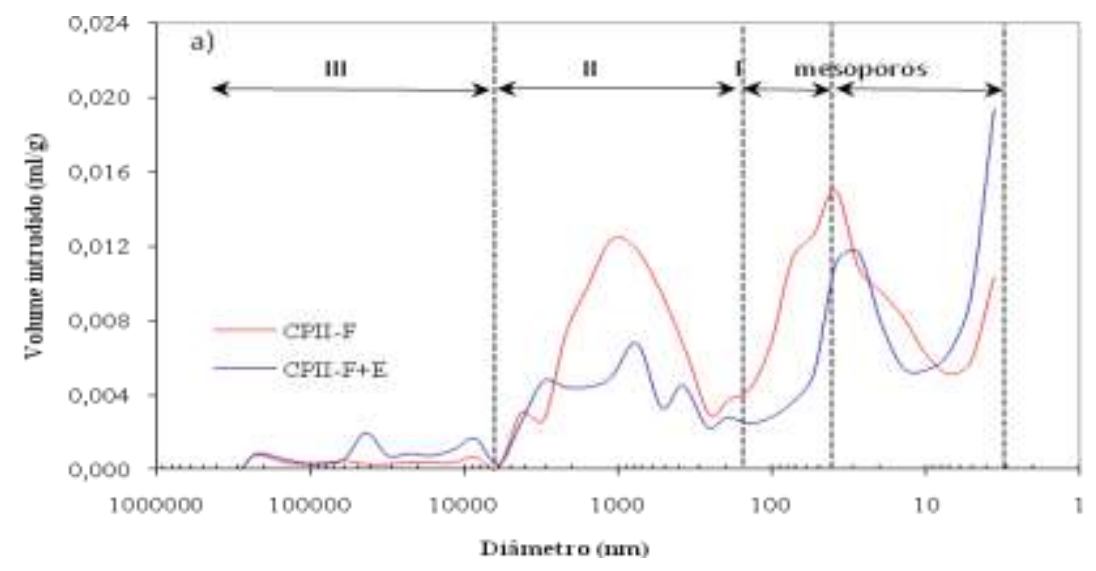

(a) Distribuição dos poros

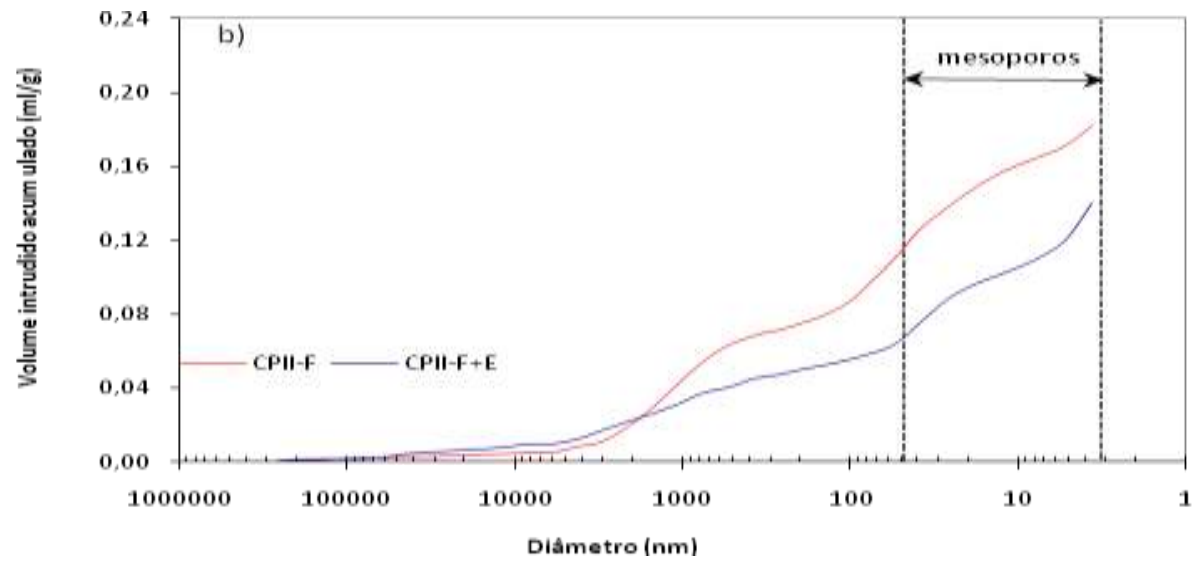

(b) Volume acumulado por faixa

Figura 3 - Caracterização dos poros

\begin{tabular}{c|c|c}
\hline & CPII F & CPII F+E \\
\hline LOP $(\mathbf{M P a})$ & $11,14 \pm 0,80$ & $12,16 \pm 0,84$ \\
\hline MOR $(\mathbf{M P a})$ & $14,82 \pm 1,35$ & $14,50 \pm 1,65$ \\
\hline MOE $(\mathbf{G P a})$ & $18,93 \pm 2,25$ & $9,01 \pm 1,14$ \\
\hline Tenacidade $\left(\mathbf{k j} / \mathbf{m}^{2}\right)$ & $1,50 \pm 0,33$ & $1,22 \pm 0,12$ \\
\hline
\end{tabular}

Tabela 3 - Valores médios e desvio padrão das propriedade mecânicas

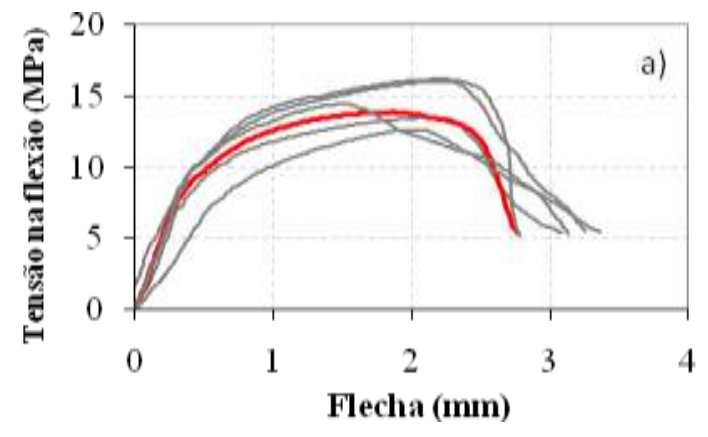

(a) Compósitos com CPII F

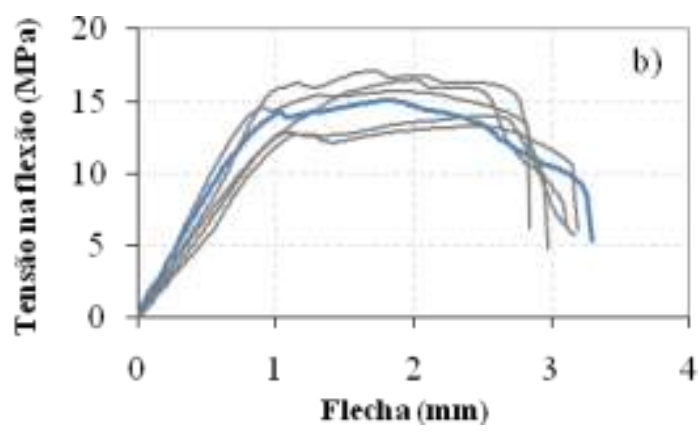

(b) Compósitos com CPII F + E

Figura 4 - Curvas tensão $x$ deslocamento 


\section{Análise termogravimétrica}

A Figura 5 apresenta as análises termogravimétricas das formulações analisadas. A linha tracejada representa a perda de massa (TG) e a linha contínua indica a perda de massa diferencial (DTG). A faixa de temperatura, 30 a $225{ }^{\circ} \mathrm{C}$, referente à decomposição da água quimicamente combinada

(TAYLOR,

1997

RAMACHANDRAN, 1969), apresentou-se 83\% maior para o CPII F+E. Isso se deve ao fato de o cimento de escória ativada formar maior quantidade de C-S-H quando comparado aos cimentos Portland. Não foi possível calcular o valor da quantidade de $\mathrm{C}-\mathrm{S}-\mathrm{H}$ presente nas amostras, pois nessa faixa de temperatura também ocorre a decomposição dos voláteis do monossulfoaluminato, aluminatos hidratados e etringita, quando houver (HOPPE FILHO, 2008; SOUZA, 2006).

A perda de massa entre 225 e $295{ }^{\circ} \mathrm{C}$, faixa de temperatura referente à decomposição da fibra de PVA, não apresentou diferença significativa entre os ligantes, visto que os teores de fibras empregados são iguais (Figura 5). Não foi observada presença de fibra de celulose na amostra CP II F+E aos 28 dias. A porosimetria de mercúrio também não mostra poros na faixa associada ao lúmen da celulose. Isso indica que o sistema escória/silicato de sódio provavelmente degrada a celulose muito rapidamente.

A Tabela 4 resume os principais resultados da termogravimetria. $\mathrm{O}$ volume de água combinada com C-S-H e aluminatos é superior no cimento $\mathrm{CPII} \mathrm{F}+\mathrm{E}$, o que é coerente com os dados de porosimetria. No compósito CPII $\mathrm{F}$ foi quantificada a perda de massa de $2,20 \%$ referente à decomposição da portlandita. Na formulação CPII $\mathrm{F}+\mathrm{E}$, a portlandita formada na hidratação do cimento Portland foi totalmente consumida durante a hidratação da escória e silicato de sódio, não tendo sido identificada pela termogravimetria. Por fim, não foi detectada qualquer diferença significativa na faixa de temperatura referente à decomposição dos carbonatos.

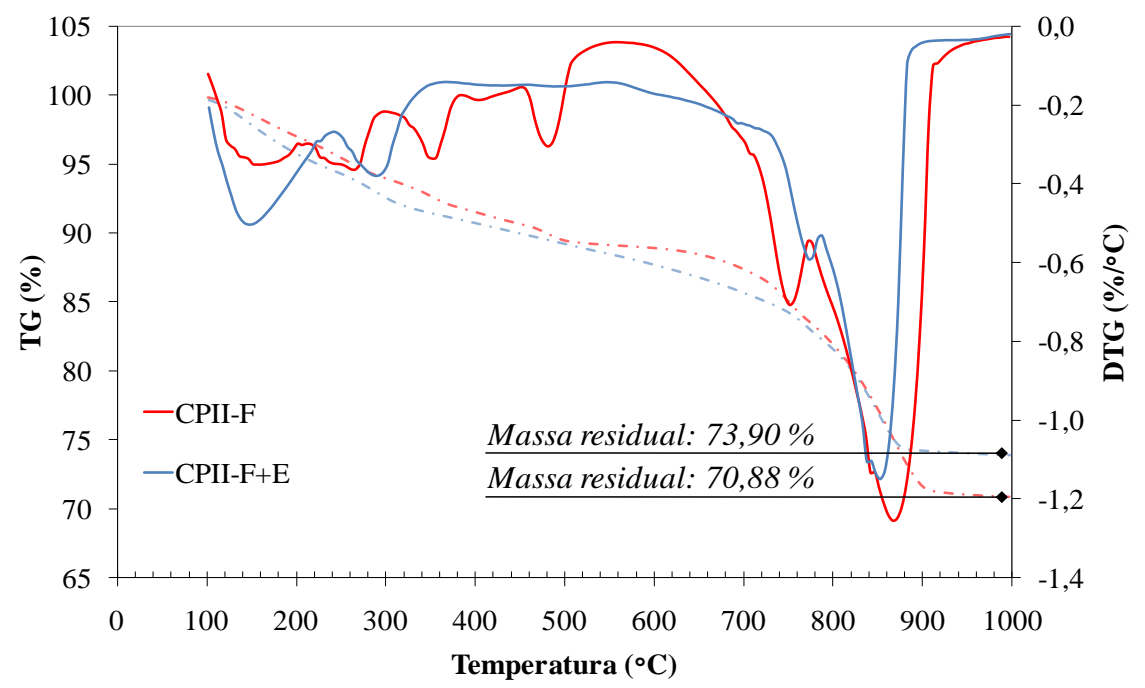

Figura 5 - Curvas de perda de massa (TG) em linhas tracejadas e derivadas da curva de perda de massa (DTG) em linhas cheias para ambos os compósitos

\begin{tabular}{c|l|c|c}
\hline Temperatura $\left({ }^{\circ} \mathbf{C}\right)$ & Principais fases decompostas & CPII F & CPII F+E \\
\hline $30-225$ & C-S-H + Aluminatos & 4,16 & 7,62 \\
\hline $225-295$ & Fibras de PVA & 4,22 & 4,75 \\
\hline $295-370$ & Fibra de celulose & 3,03 & - \\
\hline $370-420$ & Hidróxido de magnésio & 1,74 & - \\
\hline $420-580$ & Hidróxido de cálcio & 2,20 & - \\
\hline $580-1000$ & Carbonato de cálcio & 25,73 & 24,46 \\
\hline
\end{tabular}

Tabela 4 - Perdas de massa (\%) corrigidas na base não-voláteis 


\section{Retração por secagem}

As Figuras 6 e 7 apresentam os resultados de retração por secagem e umidade residual extraídas dos fibrocimentos ao longo de 28 dias. O compósito CPII F+E apresentou retração aos 28 dias aproximadamente 2,7 vezes superior ao cimento CPII $\mathrm{F}$ aos 28 dias. Esses dados são confirmados por John (1995) e Melo Neto (2002), que mostra que argamassas de cimento de escória ativada com silicato de sódio apresentam retração de 2 a 8 vezes maior que as formuladas com cimento CPV. A retração elevada para sistemas ativados por silicato de sódio é explicada pelo maior volume de C-S-H que aumenta os poros na faixa menor que $0,003 \mu \mathrm{m}$ (Tabela 2).

A retração por secagem do compósito CPII F+E é mais elevada, apesar de esta formulação ter perdido menos água e ter apresento uma umidade final bastante superior que o CPII F. Isso se deve ao fato de a água presente na mistura desse tipo de cimento gerar maior pressão capilar pelo maior teor de microporos (CHEN; BROUWERS, 2007).

\section{Conclusões}

Neste estudo foram comparados fibrocimentos produzidos usando como ligante o cimento CPII F com CPII F combinado com escória e silicato de sódio, um conhecido ativador da escória, entre camadas do corpo de prova. A mudança da composição do ligante alterou significativamente propriedades como distribuição de poros, quantidade de fases hidratadas medidas pela termogravimetria, módulo de elasticidade e retração. Não foram afetados o módulo de ruptura nem o limite de proporcionalidade na flexão.

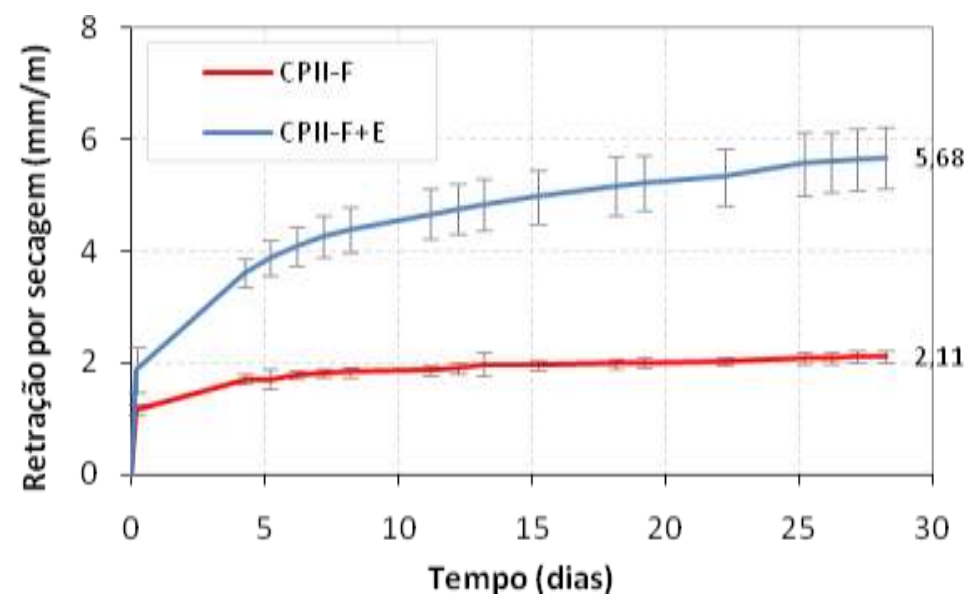

Figura 6 - Retração por secagem ao longo do tempo

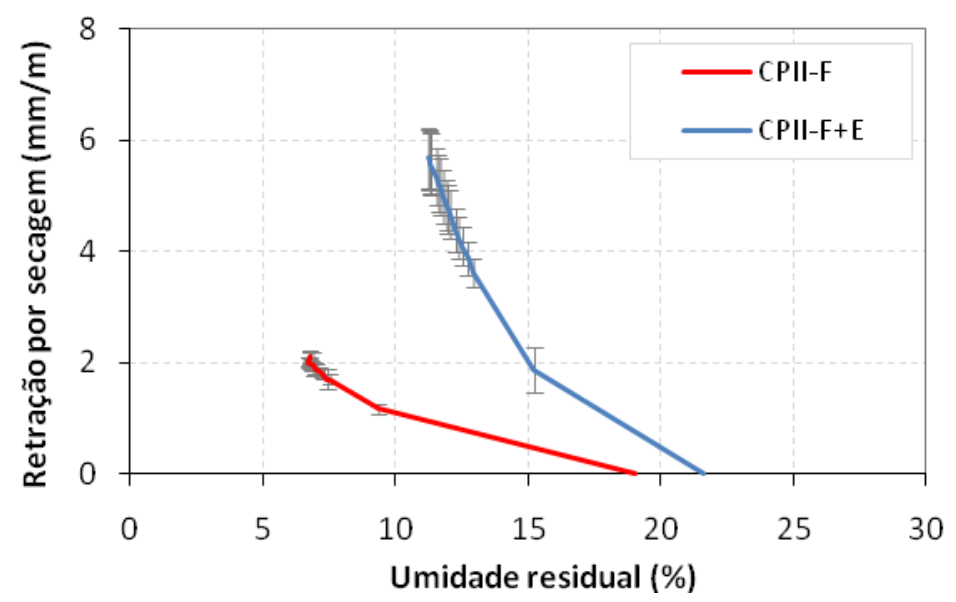

Figura 7 - Curva de secagem: retração por secagem versus umidade residual 
A formulação CPII F+E apresentou maior massa de C-S-H, confirmado pelo maior volume de poros abaixo de $0,003 \mu \mathrm{m}$ e pelos resultados da termogravimetria. Essa formulação também apresentou módulo de elasticidade na flexão significativamente inferior à CPII F, possivelmente associado a defeitos produzidos pela secagem.

Diferenças significativas foram observadas na retração por secagem das amostras estudadas, tendo as formulações contendo escória e silicato de sódio apresentado retração 2,7 vezes maior que as de cimento CPII F. Esses dados indicam que a utilização de silicato de sódio para acelerar as reações de hidratação de altos teores de escória gera compósitos com retração muito superior às observadas com cimentos CPII F, que já apresentam risco de fissuração.

É possível afirmar que, para os impactos das modificações de ligantes para processo de produção de fibrocimento, devem ser avaliados cuidadosamente, além de aspectos mecânicos, aspectos como seu impacto na retração por secagem, na distribuição dos poros, e a composição química.

\section{Referências}

ASSOCIAÇÃO BRASILEIRA DE NORMAS TÉCNICAS. NBR 5735: cimento Portland de altoforno. Rio de Janeiro, 1991.

\section{ASSOCIAÇÃO BRASILEIRA DE NORMAS}

TÉCNICAS. NBR 9778: argamassa e concreto endurecidos: determinação da absorção de água índice de vazios e massa específica. Rio de Janeiro, 2005.

AKERS, S. A. S.; GARRETT, G. G. Observations and Predictions of Fracture in Asbestos Cement Composites. Journal of Materials Science, v. 18, n. 7, p. 2209-2214, 1983.

AKERS, S. A. S.; PARTL, M. Hygral and Thermal Expansion/Shrinkage Properties of Asbestos: free fibre cement. Cement and Concrete Composites, v. 12, n. 1, p. 19-27, 1990.

CARVAlHO, J. Análise de Ciclo de Vida Ambiental Aplicada à Construção Civil: estudo de caso: comparação entre cimentos Portland com adição de resíduos. Mestrado (Dissertação em Engenharia Civil) - Escola de Engenharia, Universidade de São Paulo, São Paulo, 2002.
CHEN, W., BROUWERS, H. J. H. The Hydration of Slag: part 1: reaction models for alkali-activated slag. Journal Materials Science, v. 42, n. 2, p. 428-443, 2007.

DIAMOND, S. Mercury Porosimetry: an inappropriate method for the measurement of pore size distributions in cement-based materials. Cement and Concrete Research, v. 30, n. 10, p. 1517-1525, out. 2000.

DIAS, C. M. R. Efeitos do Envelhecimento na Microestrutura e no Comportamento Mecânico dos Fibrocimentos. Mestrado (Dissertação em Engenharia Civil) - Escola de Engenharia, Universidade de São Paulo, São Paulo, 2005.

DIAS, C. M. R. et al. Mixture Screening Design to Choose Formulations for Functionally Graded Materials. Materials Science Forum, v. 631/632, p. $65-70,2009$

\section{HOPPE FILHO, J. Sistemas Cimento, Cinza}

Volante e Cal Hidratada: mecanismo de hidratação, microestrutura e carbonatação de concreto. Tese (Doutorado em Engenharia Civil) Escola de Engenharia, Universidade de São Paulo, São Paulo, 2008.

JIMÉNEZ, A. F. et al. Microstructure Development of Alkali-Activated Fly Ash Cement: a descriptive model. Cement Concrete Research, v. 35, p. 1204-1209, 2005.

JOHN, V.M. Cimento de Escória Ativada com Silicatos de Sódio. Tese (Doutorado em Engenharia Civil) - Escola de Engenharia, Universidade de São Paulo, São Paulo, 1995.

MEHTA, P. K.; MONTEIRO, P. J. M. Concreto: microestrutura, propriedades e materiais. São Paulo: IBRACON, 2008.

MELO NETO, A. A. Estudo da Retração em Argamassa com Cimento de Escória Ativada. Mestrado (Dissertação em Engenharia Civil) Escola de Engenharia, Universidade de São Paulo, São Paulo, 2002.

MELO NETO, A. A. Influência de Aditivos Redutores e Compensadores de Retração em Argamassas e Pastas com Cimento de Escória Ativada. Tese (Doutorado em Engenharia Civil) Escola de Engenharia, Universidade de São Paulo, São Paulo, 2007. 
MELO NETO, A. A., CINCOTTO, M. A., REPETTE, W. Drying and Autogenous Shrinkage of Pastes and Mortars with Activated Slag Cement. Cement Concrete Research, v. 38, n. 4, p. 565574, abr. 2008.

RAMACHANDRAN, V. S. Applications of Differential Thermal Analysis in Cement Chemical. Nova York: Chemical Publishing Company, 1969.

ROMANO, R. C. O. et al. Influência da Técnica de Dispersão nas Propriedades de Sílica Ativa. Cerâmica, São Paulo, v. 54, n. 332, p. 456-461, 2008.

SATO, N. M. N. Análise da Porosidade e de Propriedades de Transporte de Massa em Concreto. Tese (Doutorado em Engenharia Civil) - Escola de Engenharia, Universidade de São Paulo, São Paulo, 1998.

SAVASTANO JÚNIOR, H. Desenvolvimento de Tecnologia para Fabricação de Telhas de Fibrocimento sem Amianto. Projeto FAPESP PITE 01/03833-6. São Paulo. 2001-2004.
SCRIVENER, K. L.; WIEKER, W. Advances in Hydration at Low: ambient and elevated temperatures. In: INTERNATIONAL CONGRESS ON THE CHEMISTRY OF CEMENT, 9., Nova Delhi, Índia, 1992. Anais... Nova Delhi: ICCC, 1992. v. 1, p.449-482.

SHI, C.; KRIVENKO, P. V.; ROY, D. AlkaliActivated Cements and Concretes. Londres: Taylor \& Francis, 2006.

SOUZA, R. B. Suscetibilidade de Pastas de Cimento ao Ataque por Sulfatos: método de ensaio acelerado. Mestrado (Dissertação em Engenharia Civil) - Escola de Engenharia, Universidade de São Paulo, São Paulo, 2006.

TAYLOR, H. F. W. Cement Chemistry. 2. ed. Londre: Thomas Telford, 1997.

\section{Agradecimentos}

Os autores agradecem o apoio financeiro da Fundação de Amparo à Pesquisa no Estado de São Paulo (FAPESP), à Financiadora de Estudos e Projetos (FINEP), ao Conselho Nacional de Pesquisa $(\mathrm{CNPq})$, à Infibra Ltda. (Leme, SP) e à Imbralit Ltda (Criciúma, SC). 